\title{
Comunicação em saúde entre graduandos da Faculdade de Odontologia de Piracicaba e seus pacientes.
}

\section{Rodrigo Vidal de Lima*, Beatriz Loureiro Santos, Camila Kaori Vatanabi, Prof. Dr. Fábio Luiz Mialhe.}

\section{Resumo}

No presente estudo objetivou-se avaliar as técnicas de comunicação utilizadas pelos graduandos de odontologia, incentivando-os a refletirem sobre seu atendimento, bem como analisar a maneira que os pacientes julgam ser atendidos. Foram coletados dados de 70 pacientes e 86 estudantes do terceiro, quarto e quinto ano por meio de de um questionário contendo uma escala de comunicação. Observou-se que os pacientes possuem uma visão fortemente otimista da comunicação com o estudante enquanto que ele, por sua vez, considera-se um pouco menos confiante.

\section{Palavras-chave:}

Estratégias de comunicação em saúde, estudantes de odontologia, educação em odontologia.

\section{Introdução}

A comunicação profissional-paciente é um ponto crítico em promoção de cuidados de saúde. No cenário da odontologia, é fundamental que o cirurgião-dentista possua boa habilidade de comunicação para transmitir informações de maneira adequada, o que implica numa melhor capacidade de adotar hábitos preventivos em saúde bucal por parte do paciente.

Tendo em vista esse cenário, elaborou-se o presente projeto de pesquisa que apresenta os seguintes objetivos: 1. Avaliar as técnicas de comunicação utilizadas pelos estudantes de odontologia com seus pacientes, promovendo 0 incentivo da reflexão dos alunos com relação ao seu atendimento. 2. Avaliar como os pacientes julgam/o que pensam sobre a comunicação do graduando para com eles.

\section{Resultados e Discussão}

Como metodologia, foi aplicado um questionário sociodemográfico, tanto aos graduandos quanto aos pacientes, bem como uma escala de classificação da comunicação em que o participante deveria julgar como ruim, razoável, boa, muito boa ou excelente a conduta do profissional com relação a questões do tipo "ser amigável, ajudar a lidar com a ansiedade, explicar os detalhes do procedimento".

Foram coletados dados de 70 pacientes e 86 estudantes. De maneira geral, observou-se que os pacientes eram majoritariamente do sexo feminino (63\%), brancos (71\%), com renda familiar mensal de 2 a 3 salários mínimos (48\%) e ensino fundamental completo (27\%), com idade média de 53,4 anos. No que diz respeito aos graduandos, observou-se que a maioria era branca $(90 \%)$ e do sexo feminino (69\%), com idade média de 22,6 anos.

Em se tratando da escala de classificação da comunicação, foi feita a mediana das respostas fornecidas pelos pacientes às questões do instrumento. Verificou-se que os pacientes, de forma geral, julgam como excelente a comunicação do estudante. Apenas um paciente julgou como "razoável" o relacionamento com o graduando, enquanto todos os outros apresentaram como tendências centrais (medianas) as respostas excelente ou muito bom. Por sua vez, os alunos foram menos otimistas e julgaram como muito boa suas habilidades de comunicação, não tendo diferenças estatísticas significativas entre os anos. Os resultados são mostrados no quadro 1.
Quadro 1. Mediana das respostas às questões da escala de classificação da comunicação na visão de ambos.

\begin{tabular}{|c|c|c|c|c|}
\hline \multirow[b]{3}{*}{ 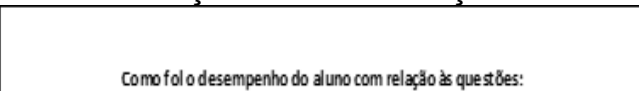 } & \multicolumn{4}{|c|}{ Medlana } \\
\hline & \multirow[t]{2}{*}{\begin{tabular}{|l|} 
Paclentes \\
\end{tabular}} & \multicolumn{3}{|c|}{ Alunos } \\
\hline & & 32 ano & $4^{8}$ ano & $5^{2}$ ano \\
\hline Fol amigével & Excelente & Excelente & Multo boa & Muito boa \\
\hline \begin{tabular}{|l|l} 
Usou um tom de vor agradável \\
\end{tabular} & Excelente & Excelente & Muito boa & Excelente \\
\hline Apresentou uma aparêncla proflsslonal & Excelente & Multo boa & Multo boa & Muito boa \\
\hline Manteve contato visual quando conve rsou com voce ou voce com ele & Excelente & Excelente & Muito boa & Muito boa \\
\hline Respeltou o seu espac pessoal & Excelente & Excelente & Muito boa & Mutto boa \\
\hline Fols sincero com vods & Excelente & Multo boa & Muito boa & Mutto boa \\
\hline Tratou vock com respelto & Excelente & Excelente & Excelente & Excelente \\
\hline Ouviu sux perguntas e preocupağes & Excelente & Excelente & Excelente & Muito boa \\
\hline 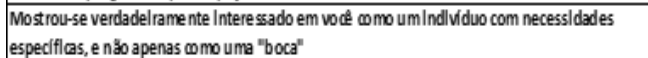 & Excelente & Excelente & Muito boa & Mutto boa \\
\hline Demonstrou esforcyo para lhe formecer umtratamento de qualldare & Excelente & Excelente & Excelente & Excelente \\
\hline Formeceu Informaç̧es Importantes sobre o que Irla acontecer na consulta & Excelente & Multo boa & Excelente & Excelente \\
\hline Per guntou sobre suas metas ou expect attvas relaclonadas a sua saúde bucal & Excelente & Multo boa & Multo boa & Muito boa \\
\hline Expllcou clar amente acondlç̧o de sua boca e dentes & Excelente & Multo boa & Multo boa & Muito boa \\
\hline 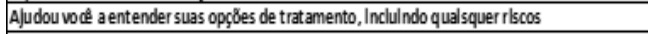 & Excelente & Mul to boa & Muito boa & Muito boa \\
\hline Certlficou-se de que vocé entendeu todas as Informaçסes fornecldas & Excelente & Multo boa & Muito boa & Muito boa \\
\hline Demonstrou $œ$ nheclmento, ou estar bem Informado, para responder sux pe rguntas & Excelente & Multo boa & Muito boa & Muito boa \\
\hline Inclulu você nas declsóes sobre o tratamento & Excelente & Multo boa & Muito boa & Muito boa \\
\hline Certificou-se de que voce estava dente dos custos do tratamento antes de Inlclá-10 & Excelente & Excelente & Muito boa & Muito boa \\
\hline Enslnou vock a culdar da sua boca sem "passar sermğo" & Excelente & Multo boa & Muito boa & Muito boa \\
\hline Expllcou clar amente o tempo necessárlo para conclulr o tratamento deste dla & Excelente & Multo boa & Multo boa & Muito boa \\
\hline Prodrou saber se vock estava ansloso ou com medo do tratamento odontologecco & Excelente & Excelente & Muito boa & Mutto boa \\
\hline A)udouvoof a aldar com qualquer ansledade ou medo emrelaç̧o ao tratamento odontol bejlco & Excelente & Multo boa & Muito boa & Mutto boa \\
\hline Expllcou o que Irla acontecer antes de cada procedlmento & Excelente & Multo boa & Muito boa & Mutto boa \\
\hline Avisou com antecedêncla quando você poderla sentlr alguma dor & Excelente & Excelente & Multo boa & Multo boa \\
\hline Perce beu se você estava sentindo al gum de sconforto & Excelente & Multo boa & Muito boa & Multo boa \\
\hline Interr ompeu o proce dlmento caso vocé estlvesse sentindo al guma dor & Excelente & Excelente & Excelente & Muito boa \\
\hline Encorajou e tran qulllirou vocé durante o tratamento & Excelente & Multo boa & Muito boa & Muito boa \\
\hline Expllcou o que você poderla se ntl r ou perce ber Imedlatamente após o tratame & Excelente & Multo boa & Muito boa & Muito boa \\
\hline GERAL & Excelente & Multo boa & Mutto boa & Mutto boa \\
\hline
\end{tabular}

\section{Conclusões}

Conclui-se que, em sua pluralidade, que os pacientes acreditam que a comunicação com o seu profissional é excelente, enquanto que os estudantes são um pouco menos confiantes julgando-a como muito boa, não havendo diferenças relevantes entre as turmas de graduação.

\section{Agradecimentos}

\section{Ao SAE e à UNICAMP;}

\footnotetext{
${ }^{1}$ Maybury, C.; Horowitz, A. M.; Wang, M. Q.; Kleinman, D. V. Use of communication techniques by Maryland dentists, 2013.

${ }^{2}$ Rozier, R. G.; Horowitz A. M.; Podschun, G. Dentist-patient communication techniques used in the United States, 2011.

${ }^{3}$ Horowitz, A. M.; Wang, M. Q; Kleinman, D. V. Opinions of Maryland Adults Regarding Communication Practices of Dentists and Staff, 2012.

${ }^{4}$ Teixeira, J. A. Carvalho. Relação técnicos de saúde-utentes, 2004.
} 